\title{
PSDB - TEORIA E ANÁLISE DOS TUCANOS
}

\section{Déberson Ferreira Jesus*}

\section{INTRODUÇÃO}

Este artigo tem por objetivo uma revisão da literatura sobre o Partido da Social Democracia Brasileira (PSDB). Fundamental e básico no trabalho acadêmico, a revisão bibliográfica deve situar o estado da arte para o entendimento e as principais contribuições preexistentes, contextualizando e identificando os avanços e limitações teóricas para o objeto de pesquisa. Deste modo, este artigo pode ser visto como uma contribuição didática e bibliográfica que ao resenhar uma série de estudos sobre o PSDB, poderá servir como ponto de partida para outras pesquisas que versem sobre o partido, bem como auxiliar no ensino sobre partidos políticos e história política recente do Brasil.

A sociedade brasileira na década de 1980 foi marcada pela transição do regime autoritário (1964-79) (Ditadura Militar) para a democracia. Durante este período nota-se a efervescência de uma sociedade civil atuando para pôr fim ao regime ditatorial e buscando intensas transformações sociais e econômicas. Neste contexto, verifica-se a atuação de diversos movimentos na sociedade civil que antes estavam marginalizados pela ditadura e com o advento da redemocratização são legitimados. Este longo processo que inicia no final da década de 1970 culmina com a proclamação da constituição de 1988. A reforma partidária teve início com a Lei nº $6.767 / 79$ que pôs fim ao bipartidarismo vigente durante a ditadura militar. Destarte, o ano de 1980 é identificado como referência inicial do retorno ao sistema multipartidário brasileiro. Com a reforma, a criação e organização de novos partidos foram possíveis, ao mesmo

\footnotetext{
* Doutorando do Programa de Pós-Graduação em Sociologia Política (PPGSP-UFSC). Licenciado em Sociologia. Bacharel em Ciência Política. Pesquisador do Instituto de Pesquisa em Riscos e sustentabilidade (IRIS-UFSC). Contato: debersonjesus@gmail.com
} 
tempo em que tornou o cenário político mais competitivo e diversificado, portanto mais condizente com as regras do jogo democrático que então se restaurava. Entretanto, os dispositivos da Lei 6.767/79 continham uma estratégia deliberada dos políticos que apoiaram o regime autoritário de dividir a oposição que estava aglutinada no MDB, observando que, a partir de meados da década de 1970, o MDB vinha capitalizando o voto do eleitorado oposicionista ao regime (LAMOUNIER, 1988; FERREIRA, 1990; KINZO 1988, 2001). Neste período, em decorrência dos fatores institucionais e históricos, o PMDB se consolida como partido catch-all $^{1}$ (pega tudo), ou partido ônibus, como definiu Fernando Henrique Cardoso para descrever o comportamento de agregação aos mais diferentes posicionamentos, visões e ideologias. A característica catch-all que, em princípio, foi um dos alegados motivos de divergência, posteriormente será utilizado para descrever as características dos novos partidos socialdemocratas e enquadrar a falta de bases operárias do partido.

Em análise sobre a evolução do sistema partidário brasileiro no período de 1982 a 2006, Ferreira et. al (2008) evidenciam os constrangimentos que marcaram o novo sistema partidário emergente:

A criação de novos partidos foi um desafio para o eleitorado, que se deparou com agremiações partidárias novas e às quais deveria adaptar-se. As exceções eram PMDB e PDS, herdeiros, respectivamente, do espólio político e eleitoral do MDB e da ARENA. Portanto, cabia aos eleitores não só buscar conhecer os novos partidos, mas distinguir as clivagens existentes entre os mesmos, seu perfil ideológico, programático e conhecer suas plataformas eleitorais. As elites políticas, por sua vez, também estavam diante de alguns desafios, dentre eles, criar e estruturar novos partidos em todo território nacional, exigência da legislação partidária. E, além disso, adaptar-se ao recém-inaugurado panorama plural da competição política, buscar um

\footnotetext{
${ }^{1}$ Nos anos 60 o cientista político Otto Kircheimer disse que os partidos da social democracia, que até a Segunda Guerra Mundial eram partidos ideológicos, estavam transformando-se em partidos do tipo catchall (um partido que "pega tudo", no sentido de "partido-ônibus"). Em outras palavras, a busca do voto deixa de focalizar setores específicos do eleitorado e passa a abranger todas as classes sociais. Timothy J. Power (“A Social Democracia no Brasil e no Mundo", Série Repensar, Instituto Teotônio Vilela, p. 5, 1997) usa uma analogia da indústria da televisão dos anos 90. Ele diz que "a mudança estratégica dos partidos social-democratas é equivalente à diferença entre a estratégia de broadcasting, um canal de TV que atrai todo mundo, e narrowcasting, os novos canais por assinatura destinados a camadas muito estreitas do mercado, tipo atletas, roqueiros e até historiadores. Os partidos catch-all adotam a estratégia de broadcasting, isto é, uma estratégia majoritária." O chamado partido catch-all (pega-tudo) tem por objetivo captar o máximo de votos, atraindo eleitores variados ou contraditórios, e portanto, deixa de assumir uma ideologia precisa.
} 
diferencial que lhes conferisse um perfil programático ou ideológico, tornar o partido conhecido do eleitorado e, sobretudo, conquistar seu apoio. No âmbito desse processo, lideranças foram reintegradas à vida pública, beneficiadas pela anistia, e procuraram se restabelecer e conquistar seu espaço na disputa política. Além disso, novos atores políticos surgiram e entraram no mercado eleitoral (FERREIRA, D. P.; BATISTA, C. M.; STABILE, M. 2008, p. 433).

Desde o período da redemocratização firmou-se no Brasil um consenso a respeito da importância dos partidos políticos como única via legítima de acesso ao poder, e efetivação do regime democrático. Todavia, apesar de crescentes, permanecem incipientes os estudos acadêmicos sobre origem, institucionalização, trajetória e atualidade dos partidos políticos no Brasil. Com exceção do Partido dos Trabalhadores (PT) que tem vasta literatura específica e comparada, na produção acadêmica são escassos os trabalhos visando à compreensão dos outros partidos em específico. Mesmo o PSDB que nas duas últimas décadas protagonizou e liderou as alianças majoritárias nas disputas eleitorais nacionais em 1994, 1998, 2002, 2006 e 2010 e ao que tudo indica em 2014, ainda não recebeu dos estudiosos de partidos um tratamento sistemático e profundo à altura de sua importância na história do Brasil.

O PSDB foi fundado em meados de $1988^{2}$, a partir de uma ala dissidente de parlamentares do PMDB no Congresso Nacional ${ }^{3}$. Existem versões contraditórias sobre as reais motivações sobre a fundação do partido. A versão oficial, ou consensual do próprio PSDB materializada na obra de Raúl Cristiano Sanches (2003) diz que apesar de vários fatores que se iniciam em 1982, quando a candidatura de Mário Covas a vicegovernador do estado de São Paulo foi substituída, numa convenção tumultuada, pelo grupo do então senador Orestes Quércia, o estopim para a criação do partido se deu por divergências ideológicas de deputados mais à esquerda com relação à aliança que o PMDB cultivava com a direita - o PFL - e em relação ao casuísmo da prorrogação do mandato presidencial para cinco anos, cujo beneficiário imediato seria o então presidente Sarney. Segundo Sanches (2003, p.19) o partido nasce "no momento em que

\footnotetext{
${ }^{2}$ Oficialmente fundado em 06 de julho de 1988. Data da publicação no Diário Oficial da União - Seção I, págs. $12508 / 12510$.

${ }^{3}$ Dos 45 parlamentares fundadores do PSDB: 38 pertenciam ao PMDB anteriormente, 4 ao PFL e o PSB, PDT e PTB tinham um parlamentar.
} 
a representação parlamentar entendeu esgotada a hipótese de fazer o Partido cumprir seu programa, uma dissidência de parlamentares à esquerda do PMDB funda o PSDB”. Celso Roma (1999, 2002) e André Guiot (2006) questionam esta tese, conforme abordaremos ao longo deste trabalho.

O PSDB é o mais novo dentre os quatro maiores partidos do Brasil (PMDB, PT, PSDB e Democratas). Contudo, não há na história brasileira, registro de um partido político que tenha crescido tão rapidamente, tanto em termos de organização quanto em resultados eleitorais. Após poucos anos de sua criação, o PSDB já venceu as eleições majoritárias presidenciais, estava presente em todo o território nacional, com mais de um milhão de filiados e vitórias sucessivas em todas as eleições realizadas desde então.

É ímpar para os estudos da realidade política do Brasil conhecer e apontar as mudanças ocorridas na trajetória do partido que venceu as eleições para presidência da república em 1994 e 1998 e foi derrotado em 2002, 2006 e 2010 ficando em $2^{\circ}$ lugar. Certamente, a derrota ou vitória do PSDB nas eleições presidenciais de 2014 abre um leque de possibilidades de pesquisa que contribuirá para os estudos sobre partidos políticos, identificação partidária, enfraquecimento ou fortalecimento dos partidos, racionalidade de decisão de voto, ideologia e pragmatismo, etc.

Identifica-se dois grupos de estudos que têm o PSDB como objeto de análise. O primeiro analisa o partido de forma direta (monográficos institucionais) e o segundo, de forma tangencial (trabalhos de análise comparativa, e/ou de comportamento eleitoral, racionalidade, ideologia). Ambos são importantes no entendimento e pesquisa à trajetória, organização e racionalidades que permeiam o discurso e ação dos tucanos.

Nos estudos monográficos institucionais destacam-se os trabalhos de Olavo Henrique Furtado (1996), Celso Roma (1997, 1999, 2002, 2004), Pomeia Genaio (2003) André Pereira Guiot (2006, 2010), Raiane Assumpção (2008, 2009) e Rodrigo Mayer (2011). Para o segundo grupo, são inúmeros os trabalhos que tangencialmente citam e de certo modo teorizam tendo o PSDB como objeto de análise em conjunto com os demais partidos do atual sistema partidário brasileiro. Dentre estes, a título de ilustração, destacam-se André Singer (2000), Eduardo Leoni (2002), Maria D’Alva Kinzo (2004,2005), Yan Carreirão (2004, 2008, 2011), José Paulo Martins Júnior (2007, 
2009, 2011), Luciana Fernandes Veiga (2007), Ednaldo Ribeiro (2011) et al. Estes trabalhos significativos de análise comparativa de comportamento eleitoral trazem dados e elementos estruturantes importantes a uma revisão teórica apurada sobre o PSDB. Neste artigo nos ateremos aos monográficos institucionais, contudo em trabalhos futuros pretende-se avançar a revisão para os estudos e análises comparativa e de comportamento eleitoral.

Importante destacar que o primeiro trabalho foi defendido em 1996 (Furtado) e a mais recente em 2011 (Mayer). Essa diferença de tempo, considerando os inúmeros fatos políticos, eleições, posicionamentos, alianças, coalizões etc. e suas respectivas consequências, deve ser considerada, problematizada e contextualizada na avaliação desses trabalhos. Destaca-se ainda que os trabalhos analisados são oriundos de diversas áreas (Ciência Política, História e Sociologia), com isso, apresentam lentes distintas sobre o mesmo objeto, levando a um maior conhecimento sobre o partido e, principalmente, sobre a história política recente do Brasil.

\section{PSDB SOCIAL-DEMOCRATA}

Um dos primeiros estudos monográficos sobre o PSDB foram realizados por Olavo Henrique Pudenci Furtado (1996), em sua dissertação de mestrado junto ao departamento de ciência política do Instituto de Filosofia e Ciências Humanas da Unicamp. Sob o título "Trajetos e perspectivas social-democratas: Do modelo europeu para o PSDB e o PT do Brasil”, já em 1996 neste estudo sobre as variáveis de social democracia no Brasil, o autor já previa/apontava que após engendrar seu processo de consolidação democrática, findado os vícios e ranços do regime militar e da transição, o sistema partidário brasileiro amadureceria e o PT e PSDB seriam os partidos que se solidificariam para liderar e protagonizar o jogo político no país. Não poderia estar mais certo.

Furtado (1996) faz uma profícua explicação sobre como a social-democracia europeia, saída da II e III internacional socialista, ajustada ao keynesianismo e colocada 
à prova pelos governos de 30, caminhou gradativamente para o abandono do marxismo. No entanto, argumenta o autor, se por um lado não-marxistas, os social-democratas, por outro, mantiveram o discurso socialista. Um discurso vinculado a uma prática democrática, reformista e compensatória inserida no contexto do capitalismo. Ou seja, uma ação transformadora em vez de rompimento com a ordem do capital.

A dissertação de Furtado conclui que apesar de "não ser socialismo", a socialdemocracia não significa adesão ao capitalismo. Em termos de proposta, ela consegue estabelecer uma diferenciação crítica ao capitalismo, porém, no campo prático, acaba dependendo involuntariamente do próprio sistema que censura. Ainda assim, o autor defende vigorosamente que dependência não significa adesão.

Através de um estudo de caso do reformismo sueco, Furtado (1996) argumenta que a social-democracia consegue aprofundar objetivos "socialistas" no capitalismo. A social-democracia, em relação ao socialismo, não é inconciliável quanto se pensa e, em relação ao capitalismo, não é tão próxima quanto seus críticos o querem impingir.

O autor dedica o capítulo V (p. 94-117) para sua (pioneira) analise teórico descritiva sobre o PSDB. Traz uma descrição histórica e argumenta sobre a origem e fundamentos do partido. Furtado (1996, p. 95) defende que a maior causa explicativa, a princípio, do surgimento do PSDB é "o descontentamento de alguns parlamentares peemedebistas com os rumos tomados pelo partido na Constituinte, principalmente em questões referentes ao sistema de governo e ao mandato presidencial de José Sarney." Em suma, o autor argumenta que os parlamentares que formaram o PSDB eram em sua maioria, "ex-peemedebistas favoráveis ao parlamentarismo e opositores ao governo Sarney. No PMDB presidencialista e tendencialmente quercista, seria impossível viabilizar a candidatura de Mario Covas à eleição presidencial de 1989. A separação foi inevitável" (FURTADO, 1996, p.95).

Neste mesmo capítulo, o autor também realiza uma análise documental do Manifesto, Estatuto e Programa do PSDB de 1988. Seu objetivo é aferir, consubstanciado a discussão sobre a nova social-democracia, através dos documentos e publicações internas ao partido, quais os pontos que caracterizem o enquadramento do partido à social-democracia. Em analise minuciosa, questionável por outras teorias, mas 
de acordo com os referenciais teóricos e práticos da nova social-democracia, Furtado defende que os documentos tucanos expressam os pensamentos da social-democracia, alertando aos desafios e problemas do Brasil. Para não se delongar, tomaremos apenas um trecho que corrobore seu argumento.

Percebe-se claramente que o PSDB procura se situar a meio caminho entre um "Estado forte e autocrático" e o "autoritarismo do mercado", ou seja, o partido é favorável ao "Estado regulador" onde assim o exigir. Em resumo: um sistema de economia mista, onde a ação estatal e a propriedade privada convivem mutuamente. “Pois nada mais social-democrata!" (FURTADO, 1996, p. 106-107).

Furtado (1996) faz uma análise empírica sobre o PT e o PSDB, ressaltando que duas situações forma vitais para suas configurações ideológicas, as eleições presidenciais de 1989 e de 1994. Em 1989 evidencia que o apoio do PSDB a Lula numa frente anti-Collor no segundo turno, demonstravam claramente que em princípio as incompatibilidades entre PSDB-PT existiam, mas não eram "letais". O apoio veio dos setores mais à esquerda com uma proposta crítica (apoio crítico como ficou conhecido) e haviam divergências programáticas explicitadas antes mesmo da formalização do apoio. Estas divergências, ou pequenas diferenças críticas de concepção estavam relacionadas a alguns dos 13 pontos apresentados pela Frente Brasil Popular, sendo eles: concepção de democracia; dívida externa; reforma agrária; sistema financeiro; privatização; capital estrangeiro; comércio exterior e política externa. Na disputa entre FHC e Lula (PSDB x PT) em 1994, mesmo tendo sido apoiados por setores vinculados a interesses divergentes, ambos estariam comprometidos com reformas sociais.

É intrigante observar que mesmo sem analisar os governos do PSDB (1995 a 2002) e do PT (2003 ao presente), Furtado (1996) conclui que as propostas do PSDB e PT, mesmo com alguns pontos discrepantes, não eram incompatíveis, ou seja, ambos partilhavam (e ainda partilham em muitos aspectos, e isso se tornou evidente com nos governos do PT) da mesma base ideológica da nova social-democracia. Um projeto que antes de mais nada, deve-se ter em mente que inexiste teoria que seja adaptável as condições nacionais sem sofrer algum tipo de modificação. Por este viés, o autor argumenta que o liberalismo não é o mesmo nos Estados Unidos e na Inglaterra, nem o 
comunismo na Europa ou da Ásia é igual ao comunismo latino. Deste modo, porque haveria de ser diferente com a social-democracia? De modo realista, e em certa medida inocente, já em 1996, Furtado defende que a proposta social-democrata do PSDB ou PT para o Brasil, poderia ser viável desde que se levasse em conta a situação nacional e não se faça uma simples transferência de modelos preconcebidos.

É importante à prática intelectual evitar sedimentar em teoria a análise de acontecimentos sociais que ainda guardam o frescor do momento. No entanto, com os dados que temos hoje, por certo se comprova a tese aventada por Furtado, e de certo modo corroborada posteriormente por Roma (1999) e Mayer (2011) e questionada por Guiot (2006).

Uma contribuição interessante de Furtado para os estudos contemporâneos é sua descrição sobre o início da ruptura e polarização entre PSDB e PT, que como dito, não são tão diferentes pragmaticamente. Segundo o autor, em 1994, uma aliança entre os dois partidos não só era possível como chegou a ser cogitada. Apesar de ambos estarem "comprometidos com reformas sociais", a "aliança reformista" não ocorreu porque tanto PSDB quanto o PT foram para o segundo turno. Furtado (1996, p. 152-153) comete um equívoco histórico grave, pois não houve segundo turno em 1994. FHC venceu as eleições no $1^{\circ}$ turno com 34.364.961 votos $(54,27 \%)$. O autor deixa a entender que somente neste inexistente segundo turno o PSDB aliou-se ao PFL e ao PTB na coligação, União, Trabalho e progresso, formando a chamada "frente de direita antiLula". No entanto, esta coligação foi aprovada em maio de 1994, na Convenção Nacional de PSDB, de modo que, contrariando parcialmente ao que argumenta Furtado, a "frente de direita" foi anterior ao governo. A outra coalizão formada pelos partidos de "esquerda" (PT/ PSB/ PCdoB/ PSTU/ PCB/ PPS) capitaneados pelo candidato do PT (Luiz Inácio Lula da Silva), "visando os eleitores de classes média, procurou de todas as formas preencher o espaço deixado pelo PSDB na centro-esquerda." (FURTADO, 1996, p. 153).

Apesar do equívoco, o que Furtado tentou demonstrar foi que como nenhum candidato conservador tinha chances reais de ir para o segundo turno, aos setores liberais e conservadores restava apoiar uma candidatura mais moderada, que nas 
condições da época, culminou ao apoio a FHC e ao PSDB. O ponto crucial é o nascimento da polarização entre PSDB e PT, que apesar da caracterização de partidos social-democratas "comprometidos com reformas sociais", é o jogo pelo poder que os coloca em lados opostos.

Com a vitória do PSDB com FHC, o programa reformista de centro-esquerda do partido se vê obrigado a dividir espaços com a "frente de direita" no governo.

Furtado talvez não tivesse a dimensão na época, mas esta aliança com alas liberais e conservadoras dará a sustentação aos governos do PSDB, contudo também ditará a guinada das políticas sociais e econômicas ao que os críticos como Guiot (2006) chamam de neoliberalismo de terceira via. O mesmo se poderia dizer sobre Lula e o PT quando chegam ao poder em 2002 com aliança com partidos conservadores e liberais, como o Partido Liberal (PL) e Partido da Mobilização Nacional (PMN). Também obteve o apoio de grupos ligados a outros partidos conservadores, como o Partido Progressista (PP), o Partido Trabalhista Brasileiro (PTB) e facções do PMDB, sobretudo os grupos ligados a Renan Calheiros e a família Sarney.

\section{PSDB PRAGMÁTICO}

Celso Roma é amplamente referenciado como um dos principais estudiosos sobre o PSDB. O interesse do autor começou já na graduação quando pesquisou a política e ideologia do PSDB, através de um estudo sobre a organização partidária dos tucanos em São Carlos-SP (ver Roma, 1997). Suas principais contribuições estão na dissertação de mestrado em Ciência Política defendida na USP em 1999, sob o título "A social-democracia no Brasil: organização, participação no governo e desempenho eleitoral do PSDB, 1988-1998" (ROMA, 1999), e nos artigos publicados, o primeiro nos anais do Anais do III Encontro Nacional da Associação Brasileira de Ciência Política - ABCP - julho de 2000, na Universidade Federal Fluminense em Niterói, "Programa partidário e ação estratégica das lideranças: PT e PSDB em perspectiva comparada" (ROMA, 2000) e o segundo (uma versão resumida e revisada de algumas 
contribuições da dissertação) na Revista Brasileira de Ciências Sociais em 2002: “A Institucionalização do PSDB, entre 1988 e 1999” (ROMA, 2002).

Roma (1999, 2002) questiona e apresenta nova explicação tanto para o surgimento quanto para a evolução do PSDB, contrariando literaturas prévias e invertendo o rumo das explicações que foram consolidadas. Quanto ao surgimento do PSDB, o autor apresenta evidências sobre a cisão do PMDB. Em sua análise, isto ocorreu mais por objetivos pragmático-eleitorais do que por divergências ideológicas. Por outro lado, em relação à sua evolução, o autor apresenta evidências de que a aliança com o $\mathrm{PFL}^{4}$ nas disputas eleitorais e na arena legislativa pode ser explicada mais por motivos ideológicos do que por motivos pragmáticos.

$\mathrm{O}$ autor defende que o PSDB foi criado por parlamentares em busca de espaço de poder, portanto, a partir de uma ação estratégica pragmática. Sua criação como partido interno ao sistema parlamentar propiciou uma estrutura organizacional fraca, descentralizada, a inexistência de atividades extra-eleitorais e pequena participação dos filiados, além da falta de instâncias democráticas de veto às decisões das elites dirigentes. Essa estrutura do PSDB, por sua vez, facilitou a aproximação entre o partido e o PFL, principalmente porque o programa de governo de ambos os partidos apresentam, segundo Roma, uma visão ideológica próxima do liberalismo.

Das análises de Roma (1999, 2002), é importante destacar a contribuição de sua pesquisa entre o tipo de estrutura organizacional do PSDB e sua ação estratégica eleitoral bem-sucedida. $\mathrm{O}$ autor confirma a hipótese de que é a facilidade que o partido teve em estabelecer alianças com maior potencial eleitoral e de governo com partidos de direita se deve ao desenho institucional de sua organização, que confere autonomia aos diretórios quando ocorrem disputas locais e centraliza a coordenação estratégica nas disputas nacionais. O PSDB segundo Roma (2002) é fracamente organizado, com seus líderes possuindo autonomia (o mesmo se dá com os Diretórios Estaduais e Municipais) e com sua organização interna possui poucas instâncias de veto. Para o autor, os programas partidários mantém uma constância, eles possuem grandes similaridades e

\footnotetext{
${ }^{4}$ O Partido mudou de nome para Democratas em convenção partidária em 2007.
} 
podem ser considerados como evoluções um dos outros, sendo que os principais aspectos são mantidos.

A argumentação de Roma (1999, 2000, 2002) é conduzida para criticar o lugarcomum de que a cultura política brasileira não se traduz em partidos coerentes ou com perfis ideológicos com alguma identidade. $\mathrm{O}$ autor já identificava nessa época a polaridade PSDB versus PT como organizada em torno a matrizes ideológicas, programáticas, de organização partidária, de alianças eleitorais e bases sociais e eleitorais que guardavam coerência com racionalidades distintas.

No artigo publicado no encontro da $\mathrm{ABCP}$, vale destacar a argumentação de que após 1994 a tradição do PSDB conciliava um programa liberal, que o aproximava do espectro de alianças de centro-direita, o partido relacionava-se mais com uma base empresarial do que com movimentos sociais, e tinha um perfil mais institucionalista e uma organização partidária com forte centralização da decisão na cúpula, apta a fazer movimentos pragmáticos eleitorais.

No artigo da Revista Brasileira de Ciências Sociais, Roma (2002) analisa a estrutura organizacional do PSDB, desde a sua fundação, em 1988, até 1999. Para tanto, o autor divide a discussão em duas partes. Na primeira, aborda analiticamente a origem, a estrutura interna de poder, a ideologia e as opiniões e atitudes políticas dos representantes eleitos. Na segunda parte, associa-se a modalidade de organização adotada pelo partido e suas consequências para a definição das suas estratégias de competição eleitoral e de participação na esfera de governo.

Os resultados da pesquisa de Roma (2002) indicam que o PSDB sofreu um processo de adaptação diante das exigências de sua sobrevivência no ambiente político no que se refere ao aumento da competitividade eleitoral e da governabilidade. Segundo os dados do autor, esse processo de adaptação pragmática, por sua vez, revela-se como uma importante variável explicativa do tipo de relação de poder entre as lideranças e os filiados e da ambiguidade entre o programa de governo e a ideologia professada. As evidências empíricas que atestam tal explicação corroboram a perspectiva teórica que pressupõe que um partido político escolhe, entre os diversos caminhos possíveis que 
permitem alcançar seus objetivos, aqueles que melhor articulem a estabilidade da organização com o acesso ao poder político.

\section{PSDB A NECESSÁRIA MODERNIZAÇÃO}

Pomeia Genaio (2003) em sua Dissertação de Mestrado apresentada ao Programa de Pós-graduação em Ciência Política, Instituto de Filosofia e Ciências Sociais, da Universidade Federal do Rio de Janeiro, intitulada "A formação do Partido da Social-Democracia Brasileira" analisou o populismo através de um estudo hemerográfico na Folha de São Paulo e no Jornal do Brasil. A dissertação faz uma rica revisão bibliográfica sobre o populismo (conceito, teoria e prática política) aponta sua construção e uso controverso no campo intelectual. De forma superficial, aponta a relação dos dissidentes do PMDB com o presidente da República, e o processo de desvinculação do grupo com o PMDB que levaram esta dissidência à posterior formação do PSDB.

Ao contrário do que sugere o título, o trabalho pouco versa sobre a formação do PSDB. O conteúdo da obra está centrada em discutir o populismo como teoria, conceito político e sua utilização no Brasil. Em que pese o texto de Genaio ser pouco articulado, a este trabalho é interessante sua contribuição empírica de verificar que a controvérsia que é marca registrada nos usos e definições do populismo no campo intelectual, não se apresenta nos usos apresentados pelo discurso jornalístico analisado. As ideias imputadas à noção de populismo giravam, em geral, em torno de uma ideia básica: o atraso. De rompante, o projeto político do PSDB se apresentava como oposto ao populismo, representava “à necessária modernização". “Aos atores e projetos que se distanciavam desse figurino restavam a desqualificação - a pecha de populismo, entre outros rótulos e estereótipos." (GENAIO, 2003, p.162).

Genaio faz críticas pouco fundamentadas em sua análise, contudo é contributiva sua conclusão de que o estudo dos casos da Folha e do JB trazem questões interessantes de como seus respectivos discursos denotam muitas afinidades com os grandes 
problemas, horizontes e reformas pró-mercado que deveriam ser operadas no país. Segundo este autor, de encontro ao discurso tucano e da "ideologia neoliberal" constituindo-se em um nítido referencial para as interpretações do cotidiano político. A “interpelação realizada por essa ideologia era evidente, entre outros, no combate aos populistas. [...] os símbolos do atraso e do estatismo consubstanciaram a representação geral da noção de populismo, construída, direta e indiretamente, por esses jornais." (GENAIO, 2003, p.162).

Neste trabalho Genaio (2003) conclui que os discursos dos jornais analisados evidenciaram uma identidade geral na representação da noção de populismo: atraso, estatismo, instabilidade, irresponsabilidade e irrealismo. Em contraponto ao entrave à modernidade, à flexibilidade produtivo-econômica, à estabilidade, à responsabilidade e ao pragmatismo, requeridos, segundo os jornais, pela "sociedade brasileira" estavam as propostas e o discurso do PSDB. Em suma, para Genaio (2003), o populismo metamorfoseou-se no discurso do Jornal do Brasil e da Folha de São Paulo em uma ferramenta ideológica importante e generalizante para a desqualificação de projetos e atores políticos que buscavam alternativas aos cânones neoliberais do PSDB.

\section{PSDB NEOLIBERAL}

A dissertação de mestrado "Um moderno príncipe para a burguesia brasileira: o PSDB (1988-2002)" e o artigo “O programa neoliberal de terceira via do PSDB (19882002)" de André Pereira Guiot (2006, 2010 respectivamente) a partir de uma base teórica marxista-gramsciana, Guiot argumenta que o PSDB, desde a sua fundação, capacitava-se para tornar-se o propagador e implementador da contrarreforma do Estado brasileiro através do programa neoliberal de tipo terceira via ${ }^{5}$. Segundo os argumentos desse autor, o programa peessedebista tinha como motivo condutor a reelaboração das novas relações entre o Estado e a sociedade civil no Brasil dos anos 90, com vistas a

\footnotetext{
${ }^{5}$ Guiot $(2006,2010)$ usa este termo para diferenciar o neoliberalismo ortodoxo e sua redefinição pensada por Antony Giddens (2001a, 2001b, 2007) e demais pensadores da nova social democracia ou terceira via.
} 
garantir a reprodução ampliada de setores hegemônicos do capital e não a melhoria das condições de vida das classes trabalhadoras.

A dissertação de Guiot (2006) realiza uma análise da proposta políticoideológica do PSDB e como a composição social (os atores políticos filiados ou relacionados com membros do partido) foi determinante para garantir a implementação dessa proposta não só no setor partidário, mas também como um projeto para o Brasil ao assumirem o governo, especialmente na instância federal. Guiot (2006) faz um exame do conteúdo social do PSDB, sobre suas bases sociais, através da investigação das associações da sociedade civil a ele coligadas, bem como dos lugares sociais ocupados por seus dirigentes.

O autor defende a tese de que a razão de existência do PSDB foi tornar-se o "moderno Príncipe" da burguesia brasileira, capaz de traduzir e unificar os anseios das diversas frações de classes dominantes em torno do modelo neoliberal de desenvolvimento e sociabilidade.

Uma das primeiras contribuições interessante de Guiot é a identificação dos quatro setores que convergem para o PSDB em seus inícios: o grupo mais diretamente vinculado à direção de FHC, que teorizava o caminho "liberal" da Terceira Via; os democratas-cristãos vinculados à liderança de Montoro; os setores vinculados a um liberalismo conservador; e, enfim, um setor mais à esquerda, agrupado no MUP (Cristina Tavares, José Paulo Bisol, entre outros). Segundo o autor, após a saída do MUP, consolida-se a liderança de FHC, que vai galvanizar posteriormente o partido com sua candidatura à Presidência.

André Guiot identifica também, seguindo a nomenclatura do sociólogo Basílio Sallum Jr., os "liberais-desenvolvimentistas", em torno da liderança de José Serra, que vão se diferenciando e disputando posições ao longo da experiência com o núcleo duro do neoliberalismo. Guiot (2006) evidencia que esses setores, não contrários à privatização nem à flexibilização dos direitos do trabalho, admitem uma maior autonomia desenvolvimentista do projeto, procurando construir linhas de fusão do capital financeiro com o grande capital industrial. 
O estudo empírico de André Guiot (2006) identifica e reconstitui a inserção social de cinquenta dirigentes que ocuparam lugares centrais nas comissões executivas do PSDB. Os dados são reveladores e intrigantes sobre a rede de grandes bancos nacionais, estrangeiros e de bancos de investimento, além de dirigentes da Federação Brasileira de Bancos e da presidência da Associação Nacional de Bancos de Investimento, que se faz representar nas direções executivas do PSDB. O autor evidencia ainda, um conjunto de figuras vinculadas ao setor financeiro que gravitam com centralidade na experiência e nas formulações do partido sem ser propriamente dirigentes do partido. A partir deste estudo, compreende-se o porquê dos setores vinculados à indústria tiveram menor peso programático no PSDB.

O debate político e ideológico muitas vezes incorpora conceitos sem um significado preciso. Esses conceitos vão sendo utilizados tanto para desqualificar um adversário quanto para afirmar vagamente uma ideia. Neste sentido, com uma argumentação cavilosa, Guiot tece críticas refinadas e contundentes ao partido e suas bases político-ideológicas fundamentadas na terceira via. Reproduz todas as críticas que autores marxistas teceram a chamada terceira via, utilizando-se das definições de Giddens (2011a e 2011b). O autor faz uma revisão teórica da terceira via com o objetivo de legitimar sua crítica. Desde o início considera este novo processo como o "envernizamento do neoliberalismo" (GUIOT, 2006, p. 55), Giddens como "um verdadeiro intelectual orgânico do capital" (idem, p. 56) e argumenta que "não há distinção orgânica entre terceira via e neoliberalismo: eles compartilham dos mesmos princípios" (idem, p. 59). Não há uma revisão efetivamente crítica, pois não se discute a fundamentação histórica, prática, factua deste movimento. ${ }^{6}$ Inclusive não reconhecendo

\footnotetext{
${ }^{6}$ Terceira Via, é um conceito recorrente nos confrontos políticos ao longo da história do século XX. Contudo, na década de 1990, o conceito de terceira via foi reconstruído por Giddens (2001a, 2001b, 2007) para designar uma postura moderna de centro-esquerda. Segundo o autor, tradicionalmente o centro-esquerda agrupava os partidos social-democratas e trabalhistas. Na esquerda ficavam os partidos socialistas e comunistas, no centro e no centro-direita os liberais e na extrema direita os nacionalistas radicais. O centro-esquerda então, representava aqueles que defendiam uma reforma social no capitalismo com o objetivo de melhorar as condições de vida dos trabalhadores, sem ruptura institucional. Tal postura diferenciava a social-democracia dos partidos socialistas e comunistas, que pregavam a revolução. Os social-democratas aceitavam como princípio fundamental que as disputas eleitorais e as regras do jogo parlamentar eram essenciais para a realização do ideal de centro-esquerda. Tal comportamento consolidou a democracia no continente europeu e obteve um enorme avanço na área social, produzindo os chamados
} 
se tratar de um movimento mundial com diversos matizes, autores e contornos, identificável, por exemplo, nos artigos do livro organizado pelo próprio Giddens (2007) "O debate global sobre a terceira via",

Guiot crítica os trabalhos de Celso Roma por enfatizar o caráter pragmático do PSDB como explicação a sua ascensão ao centro do governo do país. Em oposição a Roma, Guiot tenta demonstrar que o PSDB é orgânico à burguesia brasileira e internacional, em particular a seus setores financeiros, mobilizando quadros inseridos em vastas redes de elaboração e difusão intelectual, fornecendo um projeto capaz de, no primeiro momento, aglutinar amplos setores mercantis que se apresentavam dispersos e fragmentados após a fracassada experiência de Collor.

Apesar de muito contributivo do ponto de vista empírico, as análises de Guiot (2006, 2010) eivam de profundo ranço ideológico, pressupostos e conclusões, no mínimo controversas a uma análise que busque a objetividade científica com indispensáveis princípios da imparcialidade (não devemos conceder um privilégio àquele que conseguiu a reputação de ter ganho e de ter tido razão face a uma controvérsia política ou científica) e princípio de simetria (os mesmos tipos de causas explicam as crenças verdadeiras e as crenças falsas, devendo ambas serem analisadas igualmente).

\section{PSDB, REDES SOCIAIS E ORGANICIDADE}

Em sua tese de doutorado em Sociologia pela UNESP-Araquara, Raiane Assumpção (2008) faz uma rica análise da dinâmica organizacional do PSDB no Estado de São Paulo no período entre 1988 e 2006 com o objetivo de desenvolver um

welfare state. Contudo esta conquista teve um custo que se manifestou na elevada carga tributária, no excesso de regulamentação das relações trabalhistas e no crescimento do déficit público. Com o advento da globalização, todos estes custos foram elevados, o que favoreceu o surgimento da onda neoliberal. Ocorre, contudo, que a adoção da economia de livre-mercado também trouxe um elevado custo social jogando parcelas significativas da população na miséria e no desamparo. É nesse contexto que ressurge o conceito de terceira via como um movimento de centro-esquerda que visa produzir novas respostas para novos desafios.

${ }^{7}$ A obra é composta de diversos artigos de autores ao redor do mundo que buscam dar respostas para a construção de programas políticos que associem eficiência econômçica com justiça social. 
estudo empírico a respeito da dinâmica interna de um partido político utilizando uma abordagem organizacional, e considerando o contexto político-eleitoral, para identificar a influência da estrutura institucional e relacional nesse processo.

Através de seu estudo sobre o PSDB-SP a tese da autora é de que a estrutura e as normas institucionais de determinado partido, ou ainda os seus resultados eleitorais, seriam insuficientes para explicar tanto o funcionamento interno como o papel da organização partidária no sistema político-eleitoral. Deste modo, segundo Assumpção (2008), a dinâmica do partido decorre do resultado das relações entre os filiados, especialmente dos vínculos estabelecidos com os líderes partidários, com vistas a atender seus objetivos políticos.

A pesquisa é metodologicamente inovadora no estudo da complexa relação entre os atores e a organização partidária, especialmente por sua utilização da análise de redes. A utilização metodológica das redes políticas e sociais possibilitou a obtenção e o tratamento de dados empíricos referentes ao conjunto das relações que compõem e sustentam o poder posicional e institucional da organização partidária do PSDB, viabilizando uma compreensão significativa da complexidade existente na relação entre a atuação dos atores e a dinâmica organizacional do partido político. Por meio de uma abordagem que articula os padrões relacionais, os resultados eleitorais e a ocupação de cargos na Comissão do Diretório Estadual do PSDB, Assumpção (2008) identifica os fatores que explicam a organicidade e a capilaridade do partido em São Paulo.

Uma contribuição importante deste trabalho foi o mapeamento dos atributos e vínculos dos líderes partidários e dos membros que compuseram as diversas gestões da Comissão Executiva do diretório estadual a partir da definição do padrão relacional da organização. Através da construção de um mapeamento e análise das redes políticas e sociais, a autora revelou as posições de poder na organização e os atores que ocuparam ao longo da trajetória do partido.

A autora faz ainda um mapeamento geográfico da base eleitoral do partido e identifica a capacidade do capital político de determinados atores de influenciar os resultados eleitorais, comprovando-se a hipótese de que a dinâmica funcional do PSDB 
decorreu das relações entre os atores políticos, os quais, por sua vez, consideraram os aspectos institucionais para estabelecer as estratégias político eleitorais.

Os dados analisados pela pesquisadora demonstram associações significativas entre a composição da estrutura relacional interna do partido, ou seja, os vínculos estabelecidos a partir da influência do capital político de determinado ator ou grupo político do partido, e o desempenho eleitoral partidário, mais precisamente a configuração da base eleitoral. A análise realizada pela autora revela ainda que ocupar cargos no Diretório do partido não tem efeito direto nos resultados eleitorais, no entanto expressa e, ao mesmo tempo, possibilita, maior capital político ao ator e assim lhe atribui uma posição favorável no interior do partido.

Assumpção (2008) comprova empiricamente que concentrar a abordagem à estrutura da instituição partidária ou aos resultados eleitorais, como frequentemente ocorre nas análises a respeito dos partidos políticos brasileiros, é insuficiente para explicar a dinâmica interna dessas organizações. Para autora, seria necessário também estudar as implicações desses elementos político-institucionais na configuração da estrutura relacional interna da organização partidária para explicar os fatores determinantes da sua organicidade.

Segundo Assumpção (2008), a posição organizacional do ator foi construída por meio de seus vínculos relacionais e pelo acesso aos recursos oferecidos pela instituição. A autora conclui que esse processo constituiu o capital político que circulou no interior do partido e garantiu a sua dinâmica organizacional ao longo dos períodos analisados. Conclui ainda que a dinâmica funcional do PSDB-SP decorreu do padrão de relações estabelecido internamente, orientado pelos mecanismos institucionais e retro-alimentado pela reciprocidade do capital político. A ocupação dos espaços de poder e de cargos ou os recursos de autoridade formal, viabilizados pelo processo eleitoral, possibilitaram fortalecer a organização. Segundo a autora, essa afirmação decorre da compreensão de que a dimensão relacional foi referência para explicar a articulação existente entre os aspectos institucionais, as deliberações organizacionais e os interesses dos atores políticos. 
A pesquisa de Assumpção (2008) apresenta resultados que dialogam com o diagnóstico tecido pelos estudos de Roma (1999) e Guiot (2006), pois ambos os estudos utilizaram uma abordagem organizacional para analisar o PSDB nacionalmente.

O trabalho de Roma (1999 e 2002) indicou que a estrutura formal do partido, de forma geral, não corresponde aos processos que garantem o funcionamento da organização partidária. $\mathrm{O}$ autor identificou um descompasso entre as características definidas pelo estatuto do partido e o seu funcionamento efetivo. Roma (1999, 2002) concluiu que o partido possui uma estrutura organizacional fraca e descentralizada: o desenho institucional do partido possibilitou a ocupação dos cargos de direção por filiados com experiência em mandatos eletivos, garantindo aos seus líderes centrais o controle das decisões acerca das diretrizes político eleitorais no âmbito nacional e estadual e, aos líderes locais, a autonomia para decidir acerca de suas estratégias.

Guiot (2006) com sua análise de como a proposta político-ideológica e a composição social do PSDB foi determinante para garantir a implementação do projeto neoliberal de terceira via, reafirma o protagonismo e o controle dos líderes centrais nas decisões acerca das diretrizes político eleitorais no âmbito nacional.

Com outro recorte analítico (os dados referem-se apenas ao estado de São Paulo), Assupção (2008) também diagnosticou a incompatibilidade entre as normas institucionais e a dinâmica organizacional. Isso evidencia que as normas e a estrutura formal do PSDB não são os elementos centrais para garantir a sua dinâmica organizacional. Os resultados da pesquisadora demonstra que a dinâmica funcional nesse modelo de partido (pautado pela centralização decisória e autonomia operacional dos atores nas várias localidades e instâncias de poder) foi garantida pela efetivação das ações decorrentes das relações de poder estabelecida pelos atores que compõem a sua rede interna.

Recentemente, seguindo a linha de análise organizacional, Rodrigo Mayer (2011), com base no conceito de articulação geral ${ }^{8}$, realizou na sua dissertação de mestrado em Ciência Política na UFPR um importante e estudo comparativo sobre as

\footnotetext{
${ }^{8}$ Segundo Mayer (2011), este conceito diz respeito à complexidade organizativa das organizações partidárias, com estas podendo promover ou não uma maior participação de seus membros em seu interior.
} 
organizações internas do PT e PSDB. Este trabalho, apesar de curto (67 páginas) comparado ao que se costuma ver em dissertações na área de humanidades, para além da análise em profundidade do conceito de articulação geral, Mayer utiliza-se de bibliografias contemporâneas sobre partidos políticos (Duverger, Panebianco, Figueiredo e Limongi, Roma e outros) para examinar a influência das regulações estatais sobre eles, principalmente a lei orgânica dos partidos políticos, e os recursos distribuídos pelo Estado.

Mayer (2011) realiza uma pesquisa exploratória através das técnicas de análise de conteúdo de documentos partidários e de entrevistas em profundidade com lideranças partidárias do PT e PSDB. A partir de sua análise empírica defende que os dois partidos possuem organizações diferentes devido à influência do seu tipo originário, porém, também há aproximações entre eles devido a legislação partidária e a forma de obtenção de recursos junto ao Estado.

Mayer (2011) argumenta que o PSDB através de sua fraqueza organizacional, tal qual argumentada por Roma (2002), e da sua origem interna ao parlamento pode ser classificado como um partido de quadros, porém, essa classificação se mostra equivocada. Isto é evidenciado porque o partido não possui em seu quadro, nem na estratégia de atrair novos membros, pessoas que financiem as atividades do partido e, efetivos "notáveis" que defendam o programa partidário. O PSDB teria uma ação pragmática voltada ao sucesso eleitoral como meio de manutenção organizativa, sendo mais correto classificá-lo como um partido catch-all. O autor demonstra como o tipo da origem do PSDB influenciará toda a sua organização interna, desde os aspectos formais até os aspectos eleitorais. Nesse sentido, argumenta que o tipo de origem do PSDB exercerá influência sobre todas as suas ações partidárias.

Mayer (2011) constata que a origem e a história de cada partido exerceu grande influência sobre a forma como eles se estruturaram e se encontram organizados, mostrando que o PT em seus primeiros anos produziu uma estrutura que focou em um forte relacionamento entre o partido e as bases. Tendo seus principais recursos e sobrevivência oriundos dessa relação. Para além da captação de recursos, a legenda construiu uma organicidade que buscava englobar e dar voz às diversidades presentes 
em seu interior. Segundo os dados do autor, o PSDB, ao contrário, devido a sua origem interna fortaleceu sua parte nos governos em detrimento do seu centro partidário causando um baixo laço entre a organização e seus membros.

Mayer aponta um dado interessante, que ambos os partidos dependem cada vez mais do financiamento por parte da contribuição dos seus membros com mandatos eletivos e de transferências diretas através do fundo partidário. Nas palavras do autor, "temos uma aproximação entre os dois partidos no sentido que suas partes nos governos possuem grande importância em seu interior como uma importante fonte de financiamento das ações das legendas.” (MAYER, 2011, p. 67). O autor sustenta a hipótese de que o PT e o PSDB distanciam suas estruturas internas a partir das primeiras escolhas de seus fundadores e aproximam as mesmas pela necessidade de obtenção de recursos para seu funcionamento a partir de suas relações com o Estado. Os dados da dissertação corroboram a tese de alguns estudos (ver por exemplo, Dalton, 2000; Mair, 1994, 2003) de enfraquecimento das bases sociais dos partidos políticos e fortalecimento de suas relações organizacionais no interior do Estado. Nesta linha, na primordial análise de Mair (2003), os partidos perderam sua função representativa, enquanto fortaleceu as suas às funções processuais, passando de representantes da sociedade para a gestão do Estado, ao mesmo tempo, como parte do Estado, na medida em que estão cada vez mais dependentes, em termos de sobrevivência corporativa, do financiamento público que recebem do Estado.

Corroborando os argumentos já apresentados por outros autores como Furtado (1996), Roma (1997, 1999) e Genaio (2003), Mayer faz uma interessante síntese sobre a origem do PSDB. A origem do partido estaria ligada a três fatores principais: 1) o descontentamento de um grupo influente com os rumos do PMDB nacional e; 2) perda de espaço político de políticos influentes, estes almejavam disputar cargos mais altos e essa opção só se mostrou possível através da fundação de uma nova legenda e; 3) surgimento de um espaço político no centro através do desgaste do governo de José Sarney na presidência da República. 


\section{CONSIDERAÇÕES FINAIS}

Através da revisão da literatura, se reporta e avalia o conhecimento produzido em pesquisas prévias, destacando conceitos, procedimentos, resultados, discussões e conclusões relevantes. Este trabalho visou resenhar, até o presente, as principais contribuições dos trabalhos acadêmicos monográficos sobre o PSDB. Espera-se, através desta revisão bibliográfica contribuir para futuros estudos empíricos e auxiliar no ensino sobre partidos políticos, sistema partidário e eleitoral do Brasil. Pesquisa alguma parte do zero, mesmo que exploratória, isto é, de avaliação de uma situação concreta desconhecida, em um dado local, alguém já contribuiu ou pesquisou algo semelhante, ou mesmo complementarmente de certos aspectos da pesquisa pretendida.

Neste sentido, na procura de tais fontes, documentais ou bibliográficas, torna-se imprescindível para a não-duplicação de "lugares-comuns" no trabalho as contribuições das pesquisas bibliográficas. Assim, esta revisão pode servir, modestamente, pela curta exploração dos autores, como um norte para referências futuras e estudos sobre partidos políticos.

O valor deste trabalho está no cerne da literatura sobre o PSDB, o partido fundamental para estudos sobre os o sistema partidário, engajamento e a política em geral no Brasil, confirmado historicamente pelas disputas presidenciais de 1994, 1998, 2002, 2006 e 2010 centradas na polaridade entre coalizões lideradas por PT e PSDB, que concentraram no mínimo $70 \%$ dos votos dos eleitores brasileiros. E, ao que tudo indica, esse padrão de polarização tende a se repetir em 2014. Vivemos um ciclo político iniciado em 1994 em que o sistema partidário nacional tem se organizado, nas disputas nacionais, em torno à matriz de polarização PT versus PSDB. No PSDB há ainda um vasto "território" para agenda de pesquisa, tanto para análises organizacionais, quanto para perspectivas comparativas eleitorais.

\section{REFERÊNCIAS}


ALCANTARA SAEZ, Manoel e FREIDENBERG, Flávia. Partidos políticos na América Latina. Opinião Pública, vol.8, n.2, pp. 137-157, 2002.

ASSUMPÇÃO, Raiane Patrícia Severino. Análise organizacional do Partido da Social Democracia Brasileira no Estado de São Paulo (1988-2006). Tese de Doutorado em Sociologia na Universidade Estadual Paulista Júlio de Mesquita Filho, Araraquara-SP, 2008 .

BRAGA, M.S.S. O processo partidário-eleitoral brasileiro: Padrões de competição política (1982-2002). São Paulo: Associação Editorial Humanitas: Fapesp, 2006.

CARREIRÃO, Yan e KINZO, Maria Dalva. "Partidos políticos, preferência partidária e decisão eleitoral no Brasil (1989/2002)”. Dados, vol.47, nº.1, 2004.

. "Opiniões políticas e sentimentos partidários dos eleitores brasileiros". Opinião Pública, vol.14, nº 2, p.319-351,2008.

DALTON, R. The decline of party identifications. In: DALTON, R. e WATTENBER, M (Orgs.). Parties without partisans: Political change in advanced industrial democracies. Oxford: Oxford University Press, 2000.

FERREIRA, Denise Paiva; BATISTA, Carlos Marcos; STABILE, Max. A evolução do sistema partidário brasileiro: número de partidos e votação no plano subnacional 1982-2006. Opinião pública, vol. 14, nº 2, 2008.

Oposição e Transição Democrática: a estratégia peemedebista. Dissertação de mestrado em Ciência Política na UFRGS, Porto Alegre-RS, 1990.

FURTADO, Olavo Henrique P. Trajetos e perspectivas social-democratas: Do modelo europeu para o PSDB e o PT do Brasil. Dissertação de mestrado em Ciência Política no Instituto de Filosofia e Ciências Humanas da Unicamp, Campinas-SP, 1996. 
GENAIO, Pomeia. A formação do Partido da Social-Democracia Brasileira. Dissertação de Mestrado em Ciência Política na Universidade Federal do Rio de Janeiro. Rio de Janeiro: UFRJ/ IFCS, 2003.

GUIOT, André P. Um moderno príncipe para a burguesia brasileira: O PSDB (1988 a 2002). Dissertação de Mestrado em História na Universidade Federal Fluminense, Niterói, 2006.

GIDDENS, Anthony. A terceira via - reflexões sobre o impasse político atual e o futuro da social-democracia. Rio de Janeiro: Record, 2001 a.

A terceira via e seus críticos. Rio de Janeiro: Record, $2001 \mathrm{~b}$.

KINZO, Maria Dalva. Oposição e Autoritarismo: gênese e trajetória do MDB (19661979). São Paulo: Vértice, 1988.

Democratização Brasileira: um balanço do processo político desde a transição. São Paulo em Perspectiva, vol.14, nº 2001.

- “Os partidos no eleitorado: percepções públicas e laços partidários no Brasil”. Revista Brasileira de Ciências Sociais, vol.19, nº 54, 2005.

LAMOUNIER, B. $O$ "Brasil Autoritário" revisitado: o impacto das eleições sobre a abertura. In: STEPAN, A. (org.). Democratizando o Brasil. Rio de Janeiro: Paz e Terra, 1988.

LIMONGI, Fernando e FIGUEIREDO, Argelina. Executivo e Legislativo na Nova Ordem Constitucional. Rio de Janeiro: Editora FGV, 1999. 
MAIR, Peter. "Os partidos políticos e a democracia”. Análise Social, v. XXXVIII, n. 167, p. 277-293, 2003.

Party organizations: From civil society to the State. In: KATZ, R. e MAIR, P. (eds.). How parties organize: Change and adaptation. London: Sage Publications, 1994.

MARTINS JR., José Paulo. A disputa entre PSDB e PT nas eleições presidenciais 1994 - 2006. Tese de doutorado em Ciência Política na Universidade de São Paulo - USP, São Paulo - SP, 2007.

Modelo sociológico de decisão de voto presidencial no Brasil - 1994-2006.

Revista Debates. Porto Alegre, Núcleo de Pesquisa sobre a América Latina e PPG em Ciência Política da Universidade Federal do Rio Grande do Sul (UFRGS), v. 3, p. 6896, 2009.

MAYER, Rodrigo. Os Partidos como organizações: um estudo comparado do PSDB \& $P T$. Dissertação de mestrado em Ciência Política na Universidade Federal do Paraná, Curitiba-PR, 2011.

POWER, Timothy J. A Social Democracia no Brasil e no Mundo. Série Repensar, n², Instituto Teotônio Vilela - Seção Rio Grande do Sul, 1997.

RIBEIRO, Ednaldo; CARREIRAO, Yan; BORBA, Julian. Sentimentos partidários e atitudes políticas entre os brasileiros. Opinião Pública, vol.17, nº 2, p. 333-368, 2011.

ROMA, Celso e PERES, Paulo Sérgio. Programa partidário e ação estratégica das lideranças: PT e PSDB em perspectiva comparada. Anais do III Encontro Nacional da Associação Brasileira de Ciência Política - ABCP - julho de 2000, UFF, Niterói. 
ROMA, Celso. Política e ideologia do PSDB: um estudo sobre a organização partidária dos tucanos em São Carlos-SP, 1988-1996. Monografia de Ciências Sociais na Universidade Federal de São Carlos não publicada. São Carlos-SP, 1997.

A social-democracia no Brasil: organização, participação no governo e desempenho eleitoral do PSDB, 1988-1998. Dissertação de mestrado em Ciência Política na Universidade de São Paulo - USP, São Paulo, 1999.

A Institucionalização do PSDB, entre 1988 e 1999. Revista Brasileira de Ciências Sociais, J, vol. 17, n 49, p. 71- 92, 2002.

SANCHEZ, Raul Christiano. De volta ao começo! Raízes de um PSDB militante que nasceu na oposição. Brasília: Instituto Teôtonio Vilela, 2003.

SINGER, André. Esquerda e direita no eleitorado brasileiro. São Paulo: EDUSP, 2000.

TAVARES, José Antônio Giusti (org.). O que esperar da social-democracia no Brasil?. Brasília, Instituto Teotônio Vilela, 2003.

VEIGA, Luciana Fernandes. Os partidos brasileiros na perspectiva dos eleitores: mudanças e continuidades na identificação partidária e na avaliação das principais legendas após 2002. Opinião Pública, vol.13, nº 2, pp. 340-365, 2007. 


\title{
RESUMO
}

O objetivo do artigo é um a revisão bibliográfica exploratória da trajetória e produção acadêmica sobre o Partido da Social Democracia Brasileira (PSDB) a partir dos principais estudos monográficos. Analisam-se os trabalhos de Henrique Furtado, Celso Roma, Pomeia Genaio, André Pereira Guiot, Raiane Assumpção e Rodrigo Mayer. Destacam-se as caracterizações e constructos teóricos que tangenciam os argumentos: social-democracia, neoliberalismo, pragmatismo, partido como resposta política para modernização, as redes e bases políticas e sociais, a organicidade, a trajetória e institucionalização.

PALAVRAS-CHAVE: Partido da Social-Democracia Brasileira (PSDB). Partidos políticos. Social-Democracia.

\begin{abstract}
The objective of this paper is a literature review and exploratory trajectory of scholarship on the Party of Brazilian Social Democracy (PSDB) through the main monographic studies. The study analyzes the work of Henrique Furtado, Celso Roma Pomeia Genaio, André Pereira Guiot, Raiane Assumpção and Rodrigo Mayer. Noteworthy are the characterizations and theoretical constructs that tangent arguments: social democracy, neo-liberalism, pragmatism, party as a political response to modernization, networks and political and social bases, the organic, the trajectory and institutionalization.
\end{abstract}

KEYWORDS: Party of Brazilian Social Democracy (PSDB). Political Parties. SocialDemocracy.

Recebido em: 08 de julho de 2013

Aceito para publicação em: 21 de novembro de 2013 